\title{
3-6 yaş arası sağlıklı çocuklarda vücut kompozisyonu ve somatotip değerlerinin belirlenmesi
}

\section{Determination of body composition and somatotype measurements in healthy child between 3 and 6 years old}

\author{
Sema Polat ${ }^{\mathbb{D}}$, Ayşe Gül Uygur ${ }^{\mathbb{D}}$, Ahmet Hilmi Yücel1 ${ }^{\mathbb{D}}$ \\ 1 Cukurova Universitesi Tıp Fakültesi, Anatomi Anabilim Dalı, Adana, Türkiye
}

\section{Öz.}

Amaç: 3-6 yaş arası sağlıklı çocuklarda vücut kompozisyonu, el kavrama kuvveti ve somatotip değerleri belirlemektir.

Materyal ve Metot: Çalışmamıza 3-6 yaşlarında 73 sağlıklı çocuk (34 erkek, 39 kız) dahil edilmiştir. Çalışmaya dahil edilen çocuklarda vücut kompozisyonunu belirlemek için antropometrik ölçümler yapılmıştır. Bu ölçümlerden baş-boyun, kol ve uyluk bölgesine ait çevre ölçümleri ile dirsek ve diz eklem çap ölçümleri, el motor kavrama kuvveti ve deri altı yağ dokusu kalınlığı hesaplanmıştı. Somatotip değerler ise Heath Carter Analiz yöntemine göre belirlenmiştir.

Bulgular: Kızlarda yaş, vücut ağırlığı, boy uzunluğu ve Beden Kitle Indeksi-BKI ortalaması (standard sapma) sırasıyla $4,41(0,91)$ yll, $18,90(3,70) \mathrm{kg}, 106,90(7,04) \mathrm{cm}$ ve $16,45(2,07) \mathrm{kg} / \mathrm{m} 2 \mathrm{iken}$, aynı parametreler erkeklerde 4,50 (0,90) yıl, $18,82(3,52) \mathrm{kg}, 108,40(7,14) \mathrm{cm}$ ve $15,89(1,44) \mathrm{kg} / \mathrm{m} 2$ olarak bulunmuştur. Demografik veriler açısından her iki cinsiyet arasında anlamlı farklılığa rastlanımamışıı $(p>0,05)$. Kol çevre ölçümü ve el motor kavrama kuvveti hariç her iki cinsiyette tüm ölçüm parametrelerinde anlamlı farklılık bulunmamışır $(p>0,05)$. Aynı zamanda, endomorf, mezomorf ve ektomorf somatotip değerlerinde ise erkek ve kız öğrenciler arasında anlamlı fark bulunmuştur $(p<0,05)$.

Sonuç: Gelişimde cinsiyetler arası ortaya çıkabilecek farklılıklar puberte döneminden itibaren görülmeye başlanmaktadır. Çalışmamızda gelişim her iki cinsiyette benzerlik göstermesine rağmen, deri altı yağ dokusu ölçümleri kızlarda erkeklere göre daha fazla bulunmuştur.

Anahtar Kelimeler: Deri altı yağ dokusu kalınlığı, Antropometri, Somatotip analiz

\section{Abstract}

Background: It is to determine the body composition, hand motor grip strength and somatotype measurements in healthy child between 3 and 6 years old.

Methods: Seventy three (73) healthy child (34 boys, 39 girls) are participated in our study. Anthropometric measurements are performed to determine body composition in children included in the study. From these measurements, the circumference measurements of head and neck, arm and thigh and diameter measurements of elbow and knee, the grip of hand strength and subcutaneous fat thickness are calculated. The somatotype values are determined according to Health Carter Analysis method.

Results: Age, weight, height and body mass index-BMI (SD) are 4.41 (0.91) years, 18.90 (3.70) kg, 106.90 $(7.04) \mathrm{cm}$ ve $16.45(2.07) \mathrm{kg} / \mathrm{m} 2$ in girls, respectively whereas the corresponding values are found as 4.50 (0.90) years, $18.82(3.52) \mathrm{kg}, 108.40(7.14) \mathrm{cm}$ ve $15.89(1.44) \mathrm{kg} / \mathrm{m} 2$ in boys, respectively. Significant difference are no found between two genders about demographic data $(p>0.05)$. Significant difference are no found between girls and boys in all measurements (exclude arm circumference and hand grip strength measurements) both right and left side ( $p>0.05$ ). Also, the significant difference are found in somatotype such as endomorph, ectomorph and mesomorph between girls and boys $(p<0.05)$.

Conclusion: The differences that may occur between genders in development have been observed for puberty period. So, whereas development in this study is similar in both genders, skinfold thickness measurements were found higher in girls than boys.

Key Words: Subcutaneous fat thickness, Anthropometry, Somatotype analysis

\section{Sorumlu Yazar I \\ Corresponding Author}

Dr. Sema Polat

Cukurova Universitesi Tıp Fakültesi Anatomi Anabilim Dalı, Adana, Türkiye.

Tel: 05079942981

e-mail: sezaoz@hotmail.com

Geliş tarihi / Received: 08/02/2019

Kabul tarihi / Accepted: 10/05/2019

DOI: $10.35440 /$ hutfd. 524584 


\section{Giriş}

Vücut ölçüleri ve bu ölçümlerin birbirine oranlarında gözlenen farklııklar, toplumlara özgü standartların oluşturulmasını sağlamakla beraber bu farklılıkların, toplumun sağlık ve sosyo-ekonomik durumunun değerlendirilmesini ve her türlü alet, makine, kıyafet ve aksesuarın populasyonun özelliklerine uygun tasarımı ve üretimine olanak sağlar. Tasarımda antropometrinin uygun kullanımı sosyo-ekonomik durum, sağlık, kendini daha iyi, güvende ve rahat hissetme gibi parametrelerin iyileşmesini olumlu etkiler $(1,2)$.

Biceps, triceps, subscapular ve suprailiak bölgelerin deri altı yağ dokusu kalınlığı toplamı ile vücut dansititesi ve yağ yüzdesinin belirlenmesi için yapılan ölçümler aynı zamanda çocuklarda vücut yağ kompozisyonunun değerlendirilmesinde ve hedef ağırlığın hesaplanmasında önemli bir parametredir $(2,3)$. Somatotip, vücut tipi ya da insan vücudunun fiziksel sınıflandırması bakımından önemlidir. Vücut tipi üç ana başlıkta tanımlanabilmektedir. Endomorf tip, vücut küresel bir görünümde, yuvarlak başlı, göğüs hizasından ileri çıkmış, yağlı büyük karınlı, üst kolu ve uyluğu fazla yağlı ancak ince bilekli penguen tipli kol ve bacak şeklindedir. Illk bakışta fazla yağlı görünen bu tipte yağlar, karın ve göğüste toplanmıştır $(4,5)$. Mezomorf tip ise kas ve kemik yapısı ileri derecede göze çarpan kübik görünümlü bir tip olup, bu tiplerde baş gövdeye göre büyük, omuzlar ve göğüs geniş, kol ve bacak fazla kaslıdır. Kalp kası büyük ve az yağlıdır $(4,5)$. Ektomorf tip ince, soluk benizli, geniş alınlı, dar göğüs ve karınlı, ince kol ve bacağa sahip olan vücut tipidir. Yağsız ve kassız olmalarına karşın vücut kütlesine oranla geniş bir cilt yüzeyine sahiptirler $(4,5)$.

Vücut kitlesinin çevresel ölçümleri aynı bölgede bulunan yağ dokusu ölçümleri ve diğer çevre ölçümleri ile birlikte büyüme, beslenme ve vücut yağ dokusunun belirlenmesinde kullanilırken, vücut tipinin belirlenmesi için klinik amaçlı olarak çap ölçümleri kullanılmaktadır (2). Vücut yağ oranı doğumdan hemen sonra $(\% 12)$, 6 .ayda $(\% 30)$ ve yürüme döneminde (\%18) değişmektedir. Kızlarda ve erkeklerde göğüs ve kalça bölgesinde yaşanan büyüme ve gelişimin tamamlanması vücut yağ oranında $\% 5$ ve $\% 12$ arasında bir farklılık oluşturur $(6,7)$. Büyüme ve gelişme, genetik, hormonal ve çevresel faktörlerin etkisinde seyreden, antropometrik ölçümlerle izlenebilen bir süreçtir $(8,9)$.

Adölesan dönemde vücut ağılığı, boy uzunluğu ölçümleri ile birlikte deri altı yağ dokusu kalınlığı ölçümü büyüme ve gelişimi en iyi şekilde değerlendirmektedir. Beden kitle indeksi (BKI), erişkinlerde obeziteyi en etkili şekilde değerlendirirken, çocuklarda ve adölesanlarda erişkinlerdeki gibi doğru bilgi vermediği ve tek başına kullanılmaması gerektiği belirtilmektedir (10). Ancak, bu dönemde yapılan değerlendirmede ölçülen değerler toplum ortalaması ile karşılaştırılarak bireyin girdiği yüzdelik dilimin hesaplanması ile olmaktadır. Bu şekilde oluşturulan yüzdelik dilimler veya ortalamalar, genetik özellikler, coğrafik koşullar, kültürel ve sosyoekonomik farklılıklar gibi nedenlerle toplumlar arasında farklıık göstermektedir. Ayrıca, bu ölçümlerin bel çevresi/kalça çevresi oranı ile deri kıvrım kalınlığı ölçümleriyle desteklenerek daha doğru sonuçların elde edilebileceği gösterilmiştir (10).

Çalışmamızda, 3-6 yaş arası çocuklarda vücut ağırlığı, boy uzunluğu, BKI ölçümlerinin yanı sıra bazı bölgelerden alınan deri altı yağ dokusu, çevre ve çap ölçümleriyle büyüme ve gelişimin değerlendirilmesi amaçlanmıştır. Ayrıca çalışmamızın insan bedeninin boyutları ve yapı özelliklerine göre sınıflandırıması, vücut tiplerine uygun spor ve sanat dallarına yönlendirilmeleri hususunda antropometrik ölçümlerin yapılması ile bilimsel çalışmalara katkı sağlayacağını düşünmekteyiz.

\section{Materyal ve Metot}

Çalışmamıza 3-6 yaşlarında 73 sağlıklı birey (34 erkek, 39 kız) dahil edilmiştir. Çalışmaya dahil edilen çocuklarda vücut kompozisyonunu belirlemek için aşağıda belirtilen antropometrik ölçümler yapılmıştır.

Baş çevresi: Protuberantia occipitalis externa ile kaşların hemen üzerinden geçen en geniş bölgeden ölçüm yapılır (2).

Boyun çevresi: Cartilagio thyroidea'nın hemen altından en dar bölgeden ölçüm yapılır (2).

Kol çevresi: Ölçüm yapılan kişi ayakta olacak şekilde, kol kasılmadan, dirsek $90^{\circ}$, humerus yere paralel konuma getirilerek ve $\mathrm{m}$. biceps brachii'nin en geniş yerinden ölçüm alınır $(2,11)$.

Uyluk çevresi: Ölçüm, kişi ayakta dururken, ayakları birbirinden yaklaşık on (10) cm açık ve vücut ağırlığı iki ayağa eşit dağılmış pozisyonda iken uyluğun orta kısmından yapilir (2).

Dirsek eklem çapı: Dirsek $90^{\circ}$ fleksiyon pozisyonundayken, os humeri epicondylus medialis ve epicondylus lateralis arasındaki uzaklık ölçülür (2).

Diz eklem çapı: Kişi, dizleri $90^{\circ}$ fleksiyon pozisyonunda otururken, os femoris condylus medialis ve condylus lateralis arasındaki uzaklık ön yüzden ölçülür (2).

Deri altı yağ dokusu ölçümlerinde tutma işlemi, literatüre uygun olarak ölçüm yapılacak noktanın yaklaşık $1 \mathrm{~cm}$ uzağından, araya kas dokusu girmeyecek şekilde başparmak ile işaret parmağı arasında yapııırken, ölçüm tamamlanana kadar tutma işlemi aynı basınç korunarak devam etmiştir. Ayrıca, ölçüm, kaliper ile deri teması olduktan sonra 1-2 sn içinde gerçekleştirilir ve her bölgeden 2 defa ölçüm alınırken en yüksek ölçüm sonucu referans alınmıştır (2).

Biceps deri altı yağ dokusu ölçümü: Dirsekler ekstensiyon pozisyonunda, kollar gevşek ve gövde yanındayken, antecubital bölge ile omuz arasındaki uzaklığın orta noktasından ölçülür (2).

Triceps deri altı yağ dokusu ölçümü: Dirsekler ekstensiyon pozisyondayken, kollar gevşek ve gövde yanında, acromion ile olecranon arasındaki uzaklığın orta noktasından, 
vertikal olarak ölçülür (2).

Subscapular deri altı yağ dokusu ölçümü: Scapula'nın angulus inferior'undan vertebral kenara doğru çizilen 1-2 cm' lik çizgi üzerinden $45^{\circ}$ lik açı ile diagonal olarak ölçülür (2). Suprailiak deri altı yağ dokusu ölçümü: Anterior aksiller hattan aşağıya doğru indirilen çizginin crista iliaca üzerindeki noktasından $45^{\circ}$ lik açı ile diagonal olarak ölçülür (2). Uyluk deri altı yağ dokusu ölçümü: Ölçüm yapılan taraftaki diz hafif fleksiyon pozisyonunda, ayak yer ile temasta iken, art. coxae ve patella margo proximalis arasındaki uzaklığın orta noktasından vertikal olarak ölçülür (2).

El-Motor Kavrama Kuvveti: Dinamometre ibresi sıfırlandıktan sonra ölçüm yapılacak kişiden, aleti vücuduna değdirmeden dominant taraftan en az 2 saniye boyunca dinamometrenin sıkılması istenir ve ibrede görünen değer referans olarak alınır (12-14).

Vücut Tipinin Belirlenmesi: Somatotip değerler Heath Carter Analiz yöntemiyle belirlenmiştir (15).

\section{Endomorf:}

Endomorf: $0,1451 x-0,00068 x^{2}+0,0000014 x^{3}-0,7182$

$(x=$ triceps + subscapular + suprailiak deri altı yağ dokusu kalınlığı)

Mezomorf;

$0.858(\mathrm{E})+0.601(\mathrm{~K})+0.188(\mathrm{~A})+0.161(\mathrm{C})-0.131(\mathrm{H})$

$+4.5$

E: Humerus epikondil çapı (cm)

$\mathrm{K}$ : Femur epikondil çapı (cm)

A: Biceps çevre - (triceps deri altı yağ dokusu kalınlığı/10)

C: Uyluk çevresi - (uyluk deri altı yağ dokusu kalınlığı/10)

$\mathrm{H}$ : Boy uzunluğu $(\mathrm{cm})$

\section{Ektomorf;}

RPI: boy/ $3 \sqrt{ } /$ ilo

Eğer; RPI > 40.75 ise, Ektomorf $=0.732 \mathrm{RPI}-28.58$,

Eğer; $38.25<\mathrm{RPI}<40.75$ ise, Ektomorf= $0.436 \mathrm{RPI}-$ 17.63 ,

Eğer; $\mathrm{RPI}<38.25$ veya $\mathrm{RPI}=38.25$ ise, Ektomorf $=0.1$
Çap ölçümleri için $0.01 \mathrm{~mm}$ hassasiyete sahip dijital vernier kaliper (Mitutoyo marka), çevre ölçümleri için esnek olmayan mezura, el motor kavrama kuvveti için el dinamometresi (Lafayette marka 78010) ve deri altı yağ dokusu kalınIığı ölçümleri için Skinfold aleti (Lafayette) kullanılmıştır. Bu ölçümler yapıldıktan sonra minimum (min.), maksimum (max.), ort. (ortalama) ve standart sapma (SS) değerleri elde edildi. Verilerin istatistiksel analizi için SPSS 21.00 paket program kullanılmıştır. Kolmogorov Smirnov testine göre verilerin normal dağılıma sahip olup olmadığı belirlenmiş ve verilerin analizi için Pearson Korelasyon analizi ve Independent Samples T test kullanılımıştır. Çalışmaya dahil edilen 3-6 yaş arası çocuklarda ölçüm yapabilmek amacı ile "Girişimsel Olmayan Klinik Araştırmalar Etik Kurulu Onayı" alınmıştır. Ayrıca ölçümler yapılmadan önce çalışmaya dahil edilen çocukların ailesine "Bilgilendirimiş Gönüllü Aile Onam Formu" imzalatımıştır.

\section{Bulgular}

Yaşları 3 ile 6 arasında değişen 73 (34 erkek; 39 kız) kişi çalışmaya dahil edilmiştir. Yaş, vücut ağırlı̆̆ı, boy uzunluğu ve beden kitle indeksi karşılaştırıldığında kızlarda sırasıyla $4,41(0,91)$ yll, $18,90(3,70) \mathrm{kg}, 106,90(7,04) \mathrm{cm}$ ve $16,45(2,07) \mathrm{kg} / \mathrm{m}^{2}$ iken, aynı parametreler erkeklerde 4,50 $(0,90) \mathrm{yll}, 18,82(3,52) \mathrm{kg}, 108,40(7,14) \mathrm{cm}$ ve $15,89(1,44)$ $\mathrm{kg} / \mathrm{m}^{2}$ olarak bulunmuştur (Tablo1). Demografik veriler açısından her iki cinsiyet arasında anlamlı farklılığa rastlanılamamıştır $(p>0,05)$. Çevre ölçümlerinde (kol çevresi hariç) her iki cinsiyette anlamlı farklılık bulunmamıştır $(p>0,05)$. El motor kavrama kuvveti ölçümlerinde sağ-sol her iki cinsiyette anlamlı olarak farklı bulunmuştur $(p<0,05)$. Çap ölçümleri, deri altı yağ dokusu ölçüm parametreleri ve el kavrama kuvveti karşılaştırıldığında ise her iki cinsiyet arasında anlamlı farklılık bulunmamıştır $(p>0,05)$ (Tablo 2, Tablo 3 ve Tablo 4). ). Endomorf, mezomorf ve ektomorf somatotip değerlerinde ise erkek ve kız öğrenciler arasında anlamlı fark bulunmuştur ( $p>0,05)$ (Tablo 5).

Tablo 1. 3-6 yaş arası sağlıklı çocuklarda demografik veriler

\begin{tabular}{|c|c|c|c|c|c|c|c|}
\hline \multirow{2}{*}{$\begin{array}{l}\text { Demografik veriler } \\
\text { (39 kız; } 34 \text { erkek) }\end{array}$} & \multicolumn{2}{|c|}{ Min. } & \multicolumn{2}{|c|}{ Max. } & \multicolumn{2}{|c|}{$\begin{array}{l}\text { Ort. } \\
\text { (SS) }\end{array}$} & \multirow[t]{2}{*}{$p$} \\
\hline & $\mathrm{K} \mathrm{Iz}$ & Erkek & $\mathrm{K} \mathrm{Iz}$ & Erkek & $\mathrm{KIz}$ & Erkek & \\
\hline Yaş (yıl) & 3,00 & 3,00 & 6,00 & 6,00 & $4,41(0,91)$ & $4,50(0,90)$ & 0,673 \\
\hline Vücut ağırlığı (kg) & 11,00 & 11,00 & 30,00 & 24,00 & $\begin{array}{l}18,90 \\
(3,70)\end{array}$ & $\begin{array}{l}18,82 \\
(3,52)\end{array}$ & 0,929 \\
\hline Boy uzunluğu (cm) & 94,00 & 92,50 & 122 & 123,00 & $\begin{array}{l}106,90 \\
(7,04)\end{array}$ & $\begin{array}{c}108,40 \\
(7,14)\end{array}$ & 0,370 \\
\hline BKI (kg/m²) & 12,45 & 12,86 & 23,08 & 19,48 & $\begin{array}{l}16,45 \\
(2,07)\end{array}$ & $\begin{array}{l}15,89 \\
(1,44)\end{array}$ & 0,192 \\
\hline
\end{tabular}

Min.: Minimum; Max.: Maximum; Ort.:Ortalama; p:Anlamlılı katsayısı 
Tablo 2. 3-6 yaş arası sağlıklı çocuklarda çap ve çevre ölçümleri

\begin{tabular}{|c|c|c|c|c|c|c|c|}
\hline \multirow{2}{*}{$\begin{array}{l}\text { Veriler } \\
\text { (39 kı } 34 \text { erkek) }\end{array}$} & \multicolumn{2}{|l|}{ Min. } & \multicolumn{2}{|l|}{ Max. } & \multicolumn{2}{|l|}{$\begin{array}{l}\text { Ort. } \\
\text { (SS) }\end{array}$} & \multirow[t]{2}{*}{$p$} \\
\hline & Kız & Erkek & KIz & Erkek & KIz & Erkek & \\
\hline Dirsek çapı sağ (mm) & 39,00 & 39,00 & 57,00 & 60,00 & $\begin{array}{l}47,24 \\
(3,79)\end{array}$ & $\begin{array}{l}47,58 \\
(4,71)\end{array}$ & 0,971 \\
\hline Dirsek çapı sol (mm) & 40,00 & 38,00 & 58,00 & 61,00 & $\begin{array}{l}47,58 \\
(3,52)\end{array}$ & $\begin{array}{l}47,99 \\
(4,68)\end{array}$ & 0,672 \\
\hline $\begin{array}{l}\text { Diz eklem çapı sağ } \\
(\mathrm{mm})\end{array}$ & 55,00 & 56,00 & 120,00 & 85,00 & $\begin{array}{l}68,86 \\
(10,02)\end{array}$ & $\begin{array}{l}67,28 \\
(5,80)\end{array}$ & 0,421 \\
\hline $\begin{array}{l}\text { Diz eklem çapı sol } \\
(\mathrm{mm})\end{array}$ & 55,00 & 56,00 & 120,00 & 78,00 & $\begin{array}{l}67,97 \\
(9,89)\end{array}$ & $\begin{array}{l}66,99 \\
(5,22)\end{array}$ & 0,603 \\
\hline $\begin{array}{l}\text { Baş çevre ölçümü } \\
(\mathrm{cm})\end{array}$ & 48,00 & 47,00 & 54,00 & 54,00 & $\begin{array}{l}51,00 \\
(1,44)\end{array}$ & $\begin{array}{l}50,83 \\
(1,86)\end{array}$ & 0,659 \\
\hline $\begin{array}{l}\text { Boyun çevre ölçümü } \\
\text { (cm) }\end{array}$ & 21,00 & 22,40 & 29,00 & 30,00 & $\begin{array}{l}25,69 \\
(1,47)\end{array}$ & $\begin{array}{l}25,69 \\
(1,72)\end{array}$ & 0,991 \\
\hline $\begin{array}{l}\text { Kol çevre ölçümü sağ } \\
(\mathrm{cm})\end{array}$ & 13,10 & 13,30 & 22,00 & 20,00 & $\begin{array}{l}17,29 \\
(1,71)\end{array}$ & $\begin{array}{l}16,50 \\
(1,48)\end{array}$ & 0,038 \\
\hline $\begin{array}{l}\text { Kol çevre ölçümü sol } \\
(\mathrm{cm})\end{array}$ & 13,50 & 13,00 & 22,50 & 20,00 & $\begin{array}{l}17,30 \\
(1,71)\end{array}$ & $\begin{array}{l}16,61 \\
(1,51)\end{array}$ & 0,072 \\
\hline $\begin{array}{l}\text { Femur çevre ölçümü } \\
\text { sağ }(\mathrm{cm})\end{array}$ & 25,10 & 24,00 & 39,50 & 37,00 & $\begin{array}{l}32,12 \\
(3,05)\end{array}$ & $\begin{array}{l}31,81 \\
(3,22)\end{array}$ & 0,672 \\
\hline $\begin{array}{l}\text { Femur çevre ölçümü } \\
\text { sol }(\mathrm{cm})\end{array}$ & 24,60 & 24,00 & 39,30 & 36,50 & $\begin{array}{l}31,96 \\
(3,02)\end{array}$ & $\begin{array}{l}31,47 \\
(3,14)\end{array}$ & 0,503 \\
\hline
\end{tabular}

Tablo 3. 3-6 yaş arası sağlıklı çocuklarda deri altı yağ kalınlığı ölçümleri

\begin{tabular}{|c|c|c|c|c|c|c|c|}
\hline \multirow{2}{*}{$\begin{array}{l}\text { Veriler (mm) } \\
\text { (39 Kı;; } 34 \text { Erkek) }\end{array}$} & \multicolumn{2}{|l|}{ Min. } & \multicolumn{2}{|l|}{ Max. } & \multicolumn{2}{|l|}{ Ort. (SS) } & \multirow[t]{2}{*}{$p$} \\
\hline & Kız & Erkek & Kız & Erkek & Kız & Erkek & \\
\hline Biceps yağ ölçümü sağ & 2,00 & 2,00 & 12,00 & 9,00 & $4,28(2,16)$ & $3,82(1,53)$ & 0,306 \\
\hline Biceps yağ ölçümü sol & 2,00 & 3,00 & 10,00 & 10,00 & $4,27(1,89)$ & $3,97(1,68)$ & 0,480 \\
\hline Triceps yağ ölçümü sağ & 3,00 & 3,00 & 13,00 & 10,00 & $7,05(2,39)$ & $6,32(1,89)$ & 0,159 \\
\hline Triceps yağ ölçümü sol & 3,00 & 4,00 & 13,00 & 12,00 & $7,17(2,39)$ & $6,63(2,02)$ & 0,302 \\
\hline Femur yağ ölçümü (sağ) & 5,00 & 6,00 & 15,00 & 15,00 & $8,65(2,33)$ & $7,94(2,13)$ & 0,180 \\
\hline Femur yağ ölçümü (sol) & 5,00 & 6,00 & 16,00 & 15,00 & $8,67(2,38)$ & $8,01(1,98)$ & 0,211 \\
\hline Suprailiak yağ ölçümü (sağ) & 1,00 & 1,00 & 9,00 & 10,00 & $3,29(1,71)$ & $3,19(1,78)$ & 0,801 \\
\hline Suprailiak yağ ölçümü (sol) & 1,00 & 1,00 & 9,00 & 9,00 & $3,46(1,86)$ & $3,01(1,58)$ & 0,276 \\
\hline $\begin{array}{l}\text { Supscapular yağ ölçümü } \\
\text { (sağ) }\end{array}$ & 1,00 & 2,00 & 16,00 & 11,00 & $4,60(2,75)$ & $3,68(1,80)$ & 0,101 \\
\hline $\begin{array}{l}\text { Supscapular yağ ölçümü } \\
\text { (sol) }\end{array}$ & 1,00 & 2,00 & 15,00 & 10,00 & $4,59(2,57)$ & $3,63(1,72)$ & 0,070 \\
\hline $\begin{array}{l}\text { El motor kavrama kuvveti } \\
\text { (sağ) }(\mathrm{kg})\end{array}$ & 1,00 & 2,00 & 16,00 & 14,00 & $5,79(2,41)$ & $7,32(3,22)$ & 0,024 \\
\hline $\begin{array}{l}\text { El motor kavrama kuvveti } \\
(\mathrm{sol})(\mathrm{kg})\end{array}$ & 1,00 & 1,00 & 16,50 & 1,17 & $6,01(2,48)$ & $7,43(3,37)$ & 0,043 \\
\hline
\end{tabular}


Tablo 4. Yaşlara göre ölçüm parametreleri ortalama değerleri

\begin{tabular}{|c|c|c|c|c|c|c|c|c|}
\hline \multirow{2}{*}{$\begin{array}{l}\text { Veriler } \\
\text { KIz=39 } \\
\text { Erkek=34 }\end{array}$} & \multicolumn{2}{|l|}{ 3.yaş } & \multicolumn{2}{|l|}{ 4.yaş } & \multicolumn{2}{|l|}{ 5.yaş } & \multicolumn{2}{|l|}{ 6.yaş } \\
\hline & KIZ (9) & Erkek (6) & $\begin{array}{l}\mathrm{K} / \mathrm{Z} \\
(7)\end{array}$ & $\begin{array}{l}\text { Erkek } \\
\text { (8) }\end{array}$ & KIZ (21) & $\begin{array}{l}\text { Erkek } \\
\text { (18) }\end{array}$ & $\mathrm{K} I \mathrm{z}(2)$ & Erkek (2) \\
\hline $\begin{array}{l}\text { Vücut ağırlığı } \\
(\mathrm{kg})\end{array}$ & $\begin{array}{l}18,22 \\
(5,19)\end{array}$ & $\begin{array}{l}15,00 \\
(3,03)\end{array}$ & $\begin{array}{l}18,00 \\
(3,37)\end{array}$ & $17,63(2,77)$ & $\begin{array}{l}19,19 \\
(3,20)\end{array}$ & $\begin{array}{l}19,89 \\
(2,59)\end{array}$ & $\begin{array}{l}22,00 \\
(1,41)\end{array}$ & $\begin{array}{l}22,33 \\
(2,08)\end{array}$ \\
\hline $\begin{array}{l}\text { Boy uzunluğu } \\
\text { (cm) }\end{array}$ & $\begin{array}{l}103,89 \\
(8,02)\end{array}$ & $\begin{array}{l}99,58 \\
(4,61)\end{array}$ & $\begin{array}{l}102,43 \\
(4,12)\end{array}$ & $105,5(6,44)$ & $\begin{array}{l}108,62 \\
(6,07)\end{array}$ & $\begin{array}{l}111,56 \\
(5,12)\end{array}$ & $\begin{array}{l}118,00 \\
(0,01)\end{array}$ & $\begin{array}{l}114,00 \\
(4,36)\end{array}$ \\
\hline $\begin{array}{l}\text { Vücut kitle indeksi } \\
\left(\mathrm{kg} / \mathrm{m}^{2}\right)\end{array}$ & $\begin{array}{l}16,56 \\
(2,22)\end{array}$ & $\begin{array}{l}14,99 \\
(1,89)\end{array}$ & $\begin{array}{l}17,09 \\
(2,42)\end{array}$ & $15,76(1,36)$ & $\begin{array}{l}16,24 \\
(2,04)\end{array}$ & $\begin{array}{l}15,93 \\
(1,29)\end{array}$ & $\begin{array}{l}15,80 \\
(1,02)\end{array}$ & $\begin{array}{l}17,17 \\
(1,07)\end{array}$ \\
\hline $\begin{array}{l}\text { Biceps yağ ölçümü } \\
\text { sağ }(\mathrm{mm})\end{array}$ & $\begin{array}{l}4,89 \\
(3,55)\end{array}$ & $\begin{array}{c}3,83 \\
(1,33)\end{array}$ & $\begin{array}{l}4,29 \\
(1,98)\end{array}$ & $4,25(2,60)$ & $\begin{array}{l}4,05 \\
(1,56)\end{array}$ & $\begin{array}{l}3,61 \\
(0,98)\end{array}$ & $\begin{array}{l}4,00 \\
(0,98)\end{array}$ & $\begin{array}{l}4,33 \\
(1,15)\end{array}$ \\
\hline $\begin{array}{l}\text { Biceps yağ ölçümü } \\
\text { sol (mm) }\end{array}$ & $\begin{array}{l}5,17 \\
(2,65)\end{array}$ & $\begin{array}{l}4,33 \\
(1,63)\end{array}$ & $\begin{array}{l}4,29 \\
(1,38)\end{array}$ & $\begin{array}{l}4,13 \\
(2,53)\end{array}$ & $\begin{array}{l}3,91 \\
(1,70)\end{array}$ & $\begin{array}{l}3,83 \\
(1,47)\end{array}$ & $\begin{array}{l}4,00 \\
(0,96)\end{array}$ & $\begin{array}{l}4,67 \\
(1,53)\end{array}$ \\
\hline $\begin{array}{l}\text { Triceps yağ ölçümü } \\
\text { sağ }\end{array}$ & $\begin{array}{l}7,11 \\
(2,85)\end{array}$ & $\begin{array}{l}7,57 \\
(2,07)\end{array}$ & $\begin{array}{l}8,43 \\
(3,55)\end{array}$ & $5,75(2,44)$ & $\begin{array}{l}6,52 \\
(1,69)\end{array}$ & $\begin{array}{l}6,06 \\
(1,43)\end{array}$ & $\begin{array}{l}7,50 \\
(0,71)\end{array}$ & $\begin{array}{l}7,67 \\
(1,53)\end{array}$ \\
\hline $\begin{array}{l}\text { Triceps yağ ölçümü } \\
\text { sol (mm) }\end{array}$ & $\begin{array}{l}7,83 \\
(2,74)\end{array}$ & $\begin{array}{l}7,42 \\
(1,74)\end{array}$ & $\begin{array}{l}8,29 \\
(3,45)\end{array}$ & $6,25(2,60)$ & $\begin{array}{l}6,52 \\
(1,60)\end{array}$ & $\begin{array}{l}6,44 \\
(1,98)\end{array}$ & $\begin{array}{l}7,00 \\
(1,41)\end{array}$ & $\begin{array}{l}8,33 \\
(1,15)\end{array}$ \\
\hline $\begin{array}{l}\text { Femur yağ ölçümü } \\
\text { (sağ) }(\mathrm{mm})\end{array}$ & $\begin{array}{l}8,00 \\
(2,24)\end{array}$ & $\begin{array}{l}7,83 \\
(1,17)\end{array}$ & $\begin{array}{l}9,71 \\
(3,90)\end{array}$ & $8,00(3,02)$ & $\begin{array}{l}8,40 \\
(1,46)\end{array}$ & $\begin{array}{l}8,06 \\
(2,04)\end{array}$ & $\begin{array}{l}10,50 \\
(0,71)\end{array}$ & $\begin{array}{l}8,00 \\
(1,00)\end{array}$ \\
\hline $\begin{array}{l}\text { Femur yağ ölçümü } \\
\text { (sol) (mm) }\end{array}$ & $\begin{array}{l}7,78 \\
(2,39)\end{array}$ & $\begin{array}{l}7,83 \\
(1,17)\end{array}$ & $\begin{array}{l}9,57 \\
(3,95)\end{array}$ & $8,38(2,92)$ & $\begin{array}{l}8,57 \\
(1,66)\end{array}$ & $\begin{array}{l}7,81 \\
(1,89)\end{array}$ & $\begin{array}{l}10,50 \\
(0,71)\end{array}$ & $\begin{array}{l}8,33 \\
(0,58)\end{array}$ \\
\hline $\begin{array}{l}\text { Suprailiak yağ öl- } \\
\text { çümü (sağ) (mm) }\end{array}$ & $\begin{array}{l}4,33 \\
(2,45)\end{array}$ & $\begin{array}{l}4,17 \\
(2,32)\end{array}$ & $\begin{array}{l}4,21 \\
(2,04)\end{array}$ & $3,44(2,82)$ & $\begin{array}{l}2,62 \\
(0,74)\end{array}$ & $\begin{array}{l}2,83 \\
(0,99)\end{array}$ & $\begin{array}{l}2,50 \\
(0,71)\end{array}$ & $\begin{array}{l}3,33 \\
(0,58)\end{array}$ \\
\hline $\begin{array}{l}\text { Suprailiak yağ öl- } \\
\text { çümü (sol) (mm) }\end{array}$ & $\begin{array}{l}4,89 \\
(2,42)\end{array}$ & $\begin{array}{l}3,92 \\
(1,80)\end{array}$ & $\begin{array}{l}4,29 \\
(2,06)\end{array}$ & $3,50(2,33)$ & $\begin{array}{l}2,62 \\
(1,02)\end{array}$ & $\begin{array}{l}2,50 \\
(0,98)\end{array}$ & $\begin{array}{l}3,00 \\
(0,78)\end{array}$ & $\begin{array}{l}3,33 \\
(0,58)\end{array}$ \\
\hline $\begin{array}{l}\text { Supscapular yağ öl- } \\
\text { çümü (sağ) (mm) }\end{array}$ & $\begin{array}{l}5,78 \\
(4,44)\end{array}$ & $\begin{array}{l}4,00 \\
(1,26)\end{array}$ & $\begin{array}{l}5,21 \\
(2,27)\end{array}$ & $3,90(3,07)$ & $\begin{array}{l}4,00 \\
(1,92)\end{array}$ & $\begin{array}{l}3,56 \\
(1,38)\end{array}$ & $\begin{array}{l}3,50 \\
(0,71)\end{array}$ & $\begin{array}{l}3,67 \\
(0,58)\end{array}$ \\
\hline $\begin{array}{l}\text { Supscapular yağ öl- } \\
\text { çümü (sol) (mm) }\end{array}$ & $\begin{array}{l}5,78 \\
(3,83)\end{array}$ & $\begin{array}{l}4,00 \\
(1,55)\end{array}$ & $\begin{array}{l}5,29 \\
(2,14)\end{array}$ & $3,69(2,74)$ & $\begin{array}{l}3,90 \\
(1,97)\end{array}$ & $\begin{array}{l}3,64 \\
(1,42)\end{array}$ & $\begin{array}{l}4,00 \\
(1,41)\end{array}$ & $\begin{array}{l}3,33 \\
(0,58)\end{array}$ \\
\hline $\begin{array}{l}\text { El motor kavrama } \\
\text { kuvveti (sağ) }(\mathrm{kg})\end{array}$ & $\begin{array}{l}3,83 \\
(2,12)\end{array}$ & $\begin{array}{l}4,92 \\
(2,06)\end{array}$ & $\begin{array}{c}4,43 \\
(1,10)\end{array}$ & $5,69(2,28)$ & $\begin{array}{l}7,02 \\
(2,19)\end{array}$ & $\begin{array}{l}8,11 \\
(2,75)\end{array}$ & $\begin{array}{l}6,50 \\
(0,71)\end{array}$ & $\begin{array}{l}11,00 \\
(5,80)\end{array}$ \\
\hline $\begin{array}{l}\text { El motor kavrama } \\
\text { kuvveti (sol) (kg) }\end{array}$ & $\begin{array}{l}4,22 \\
(2,06)\end{array}$ & $\begin{array}{l}4,08 \\
(2,11)\end{array}$ & $\begin{array}{l}4,21 \\
(1,15)\end{array}$ & $6,31(2,12)$ & $\begin{array}{l}7,14 \\
(2,15)\end{array}$ & $\begin{array}{l}8,14 \\
(3,18)\end{array}$ & $\begin{array}{l}8,50 \\
(0,71)\end{array}$ & $\begin{array}{l}11,67 \\
(3,21)\end{array}$ \\
\hline
\end{tabular}

Tablo 5. Endomorf, mezomorf ve ektomorf değerlerinin cinsiyete göre ortalama değerleri

\begin{tabular}{|c|c|c|c|}
\hline Vücut tipi & $\begin{array}{l}\text { Kız } \\
\text { Ort } \pm S S\end{array}$ & $\begin{array}{l}\text { Erkek } \\
\text { Ort } \pm S S\end{array}$ & $P$ \\
\hline Ektomorf & $1,41 \pm 1,11$ & $2,03 \pm 1,21$ & $<0,001$ \\
\hline Mezomorf & $2,87 \pm 0,51$ & $2,94 \pm 1,02$ & 0,53 \\
\hline Endomorf & $2,05 \pm 0,41$ & $2,63 \pm 0,63$ & 0,038 \\
\hline
\end{tabular}

\section{Tartışma}

Dünyada en büyük sağlık problemlerinden biri olan obezite; diyabet, koroner arter hastalı̆ı̆, hipertansiyon, kanser ve osteoartrit gibi hastalıklar için önemli bir risk faktörü oluşturmaktadır (16). Vücut ağırlığı ve boy uzunluğunun hesaplanması ile elde edilen BKI, erişkinlerde obezitenin etkili bir şekilde değerlendirilmesine yardımcı olurken, çocuklarda ve adölesanlarda vücut gelişimini tamamlamış olması gerektiği için erişkinlerdeki gibi doğru bilgi vermediği ve tek başına kullanılmadığı belirtilmektedir (10). Ancak, bu dönemde yapılan değerlendirmede ölçülen değer, toplum ortalaması ile karşılaştırılarak bireyin girdiği yüzdelik dilimin hesaplanması ile olmaktadır. Bu şekilde oluşturulan yüzdelik dilimler veya ortalamalar, genetik özellikler, kültürel ve sosyoekonomik farklılıklar gibi nedenlerle toplumlar arasında farklılık göstermektedir. Ayrıca, bu ölçümlerin bel çevresi/kalça çevresi oranı ile deri altı yağ dokusu kalınlığı ölçümleriyle desteklenerek daha doğru sonuçların elde edilebileceği gösterilmiştir (10). Yapılan bir çalışmada, yaş, cinsiyet, ırk, sosyokültürel düzey, beslenme alışkanlığı ve genetik gibi faktörlerin BKI değerini etkilediği ve BKI ölçümünün 10-75 persentil değerleri arasında normal kabul edildiği, 85 ve 95 persentile denk gelen ölçüm değerlerinin ise klinik açıdan önemli olduğu bildirilmiştir (17). 
Tablo 6. Bulguların literatür ile karşılaştırıması

\begin{tabular}{|c|c|c|c|c|c|c|c|c|c|c|}
\hline Kaynak & Veriler & Yaş Ort. & VA & $B U$ & BKI & $\begin{array}{l}\text { Bdydk } \\
(\mathrm{mm})\end{array}$ & $\begin{array}{l}\text { Tdydk } \\
(\mathrm{mm})\end{array}$ & Sidydk & Ssdydk & $\mathrm{KÇ}(\mathrm{cm})$ \\
\hline \multirow{2}{*}{$\begin{array}{l}\text { Yosmaoğlu ve } \\
\text { ark. } 2010(10)\end{array}$} & $\mathrm{K} \mathrm{IZ}$ & 11,98 & 65,24 & 153,22 & 27,46 & - & 25,1 & 40,2 & - & - \\
\hline & Erkek & 12,46 & 72,38 & 156,62 & 28,90 & - & 25,1 & - & 27,5 & - \\
\hline \multirow{2}{*}{$\begin{array}{l}\text { Sarıtekin ve Din- } \\
\text { dar } 2013 \text { (17) }\end{array}$} & $\mathrm{KIZ}$ & $2-6 \mathrm{yll}$ & 19,6 & 109,3 & 16,3 & - & 10,6 & & & 16,79 \\
\hline & Erkek & & 20,1 & 109,1 & 16,7 & - & 10,3 & & & 16,92 \\
\hline \multirow{2}{*}{$\begin{array}{ll}\text { Özdemir } & \text { MS. } \\
2014 \text { (11) } & \end{array}$} & $\mathrm{K} \mathrm{IZ}$ & $3-5 \mathrm{yll}$ & - & - & - & - & - & - & - & $15,4-16,5$ \\
\hline & Erkek & & - & - & - & - & - & - & - & $15,5-16,0$ \\
\hline \multirow{4}{*}{$\begin{array}{l}\text { Khadilkar et al } \\
2015 \text { (3) }\end{array}$} & $\mathrm{KIZ}$ & $5 \mathrm{yıl}$ & 19,3 & 111,3 & 15,5 & - & 9,4 & - & - & - \\
\hline & & 6 yıl & 21,3 & 116,9 & 15,6 & - & 9,8 & - & - & - \\
\hline & Erkek & 5 & 19,5 & 112,4 & 15,3 & - & 8,3 & - & - & - \\
\hline & & 6 & 21,7 & 117,8 & 15,5 & - & 8,9 & - & - & - \\
\hline \multirow{2}{*}{$\begin{array}{l}\text { Özkoçak ve ark. } \\
2018 \text { (22) }\end{array}$} & $\mathrm{KIZ}$ & $8,85 \mathrm{yll}$ & 34,42 & 132,62 & - & - & 12,71 & 11,80 & 10,89 & 21,95 \\
\hline & Erkek & $8,30 \mathrm{yll}$ & 33,53 & 131,56 & - & - & 11,93 & 10,98 & 9,79 & 21,54 \\
\hline \multirow{12}{*}{$\begin{array}{l}\text { Kavak V. } 2006 \\
\text { (6) }\end{array}$} & & $10 \mathrm{yll}$ & 32,9 & 137,2 & 17,5 & 8,2 & 14,2 & 9,5 & 9,6 & - \\
\hline & & $11 \mathrm{yll}$ & 34,8 & 139,7 & 17,8 & 7,4 & 13,2 & 10,6 & 9,9 & - \\
\hline & $\mathrm{K} I \mathrm{Z}$ & $12 \mathrm{yll}$ & 38,4 & 145,2 & 18,2 & 7,6 & 13,4 & 9,8 & 9,7 & - \\
\hline & & $13 \mathrm{yll}$ & 45,0 & 152,1 & 19,5 & 8,9 & 14,5 & 11,7 & 14,3 & - \\
\hline & & $14 \mathrm{yll}$ & 48,7 & 155,0 & 20,3 & 9,6 & 16,3 & 14,1 & 13,5 & - \\
\hline & & $15 \mathrm{yll}$ & 51,8 & 156,6 & 21,1 & 10,5 & 17,5 & 14,6 & 15,5 & - \\
\hline & & $10 \mathrm{yıl}$ & 32,8 & 137,3 & 17,4 & 8,2 & 13,2 & 9,5 & 9,1 & - \\
\hline & & $11 \mathrm{yll}$ & 33,9 & 139,1 & 17,6 & 6,6 & 11,1 & 8,9 & 8,2 & - \\
\hline & Erkek & $12 \mathrm{yıl}$ & 38,7 & 144,6 & 18,5 & 7,5 & 12,8 & 10,3 & 9,1 & - \\
\hline & & $13 \mathrm{yll}$ & 43,3 & 151,6 & 18,8 & 8,0 & 12,7 & 10,2 & 9,3 & - \\
\hline & & $14 \mathrm{yll}$ & 46,9 & 156,2 & 17,6 & 8,6 & 12,0 & 10,9 & 9,7 & - \\
\hline & & $15 \mathrm{yıl}$ & 52,0 & 162,8 & 19,6 & 7,0 & 9,1 & 7,5 & 7,7 & - \\
\hline \multirow{2}{*}{$\begin{array}{l}\text { Çiçek ve ark.ları } \\
2014(24)\end{array}$} & $\mathrm{KIZ}$ & $6 \mathrm{yll}$ & - & - & - & 5,78 & 10,03 & 4,98 & 5,99 & - \\
\hline & Erkek & & - & - & - & 5,41 & 8,66 & 4,43 & 5,70 & - \\
\hline \multirow{2}{*}{$\begin{array}{l}\text { Deurenberg ve } \\
\text { ark.ları } 1990(23)\end{array}$} & $\mathrm{K} \mathrm{IZ}$ & Puberte & - & - & - & 6.6 & 11.9 & 9.7 & 7.1 & - \\
\hline & Erkek & öncesi & - & - & - & 5.3 & 9.5 & 7.6 & 6.2 & - \\
\hline \multirow{2}{*}{$\begin{array}{l}\text { Jenhek and De- } \\
\text { mirciyan } 1972 \\
\text { (19) }\end{array}$} & $\mathrm{K} \mathrm{IZ}$ & & - & - & 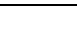 & - & 8,03 & - & 5,92 & - \\
\hline & Erkek & $6 \mathrm{yıl}$ & - & - & - & - & 9,60 & - & 6,68 & - \\
\hline \multirow{12}{*}{$\begin{array}{l}\text { Addo ve Himes } \\
2010 \text { (18) }\end{array}$} & $\mathrm{KIZ}$ & $1,5 \mathrm{yll}$ & - & - & - & - & 9,75 & - & - & - \\
\hline & & $2 \mathrm{yll}$ & - & - & - & - & 9,66 & - & - & - \\
\hline & & 3 yıl & - & - & - & - & 9,31 & - & - & - \\
\hline & & $4 \mathrm{yll}$ & - & - & - & - & 8,99 & - & - & - \\
\hline & & $5 \mathrm{yll}$ & - & - & - & - & 8,63 & - & - & - \\
\hline & & $6 \mathrm{yll}$ & - & - & - & - & 8,30 & - & - & - \\
\hline & Erkek & $1,5 \mathrm{yıl}$ & - & - & - & - & 5,84 & - & - & - \\
\hline & & 2 yıl & - & - & - & - & 5,78 & - & - & - \\
\hline & & 3 yıl & - & - & - & - & 5,51 & - & - & - \\
\hline & & $4 \mathrm{yıl}$ & - & - & - & - & 5,26 & - & - & - \\
\hline & & 5 yıl & - & - & - & - & 5,02 & - & - & - \\
\hline & & $6 \mathrm{yıl}$ & - & - & - & - & 4,79 & - & - & - \\
\hline \multirow{6}{*}{$\begin{array}{lr}\text { Marrodăn ve } \\
\text { ark.ları } 2015(20)\end{array}$} & $\mathrm{K} I \mathrm{Z}$ & $4 \mathrm{yll}$ & - & - & - & - & 11,17 & - & 7,12 & - \\
\hline & & $5 \mathrm{yıl}$ & - & - & - & - & 10,59 & - & 6,97 & - \\
\hline & & $6 \mathrm{yıl}$ & - & - & - & - & 10,23 & - & 6,96 & - \\
\hline & Erkek & $4 \mathrm{yıl}$ & - & - & - & - & 8,30 & - & 5,49 & - \\
\hline & & $5 \mathrm{yll}$ & - & - & - & - & 8,59 & - & 5,79 & - \\
\hline & & $6 \mathrm{yll}$ & - & - & - & - & 9,04 & - & 6,15 & - \\
\hline \multirow{2}{*}{$\begin{array}{l}\text { Ojo ve Adetola } \\
2017 \text { (16) }\end{array}$} & $\mathrm{KIZ}$ & $16-25 \mathrm{yll}$ & - & - & - & - & 17,82 & - & 18,63 & - \\
\hline & Erkek & & - & - & - & - & 11,10 & - & 7,05 & - \\
\hline \multirow[t]{4}{*}{ Mevcut çalışma } & $\mathrm{KIZ}$ & & 18,90 & 106,9 & 16,45 & 4,28 (sağ) & 7,05 (sağ) & 3,29 & 4,60 & 17,29 (sağ) \\
\hline & & 3-6 yıl & & & & 4,27 (sol) & 7,17 (sol) & 3,46 & 4,59 & 17,30 (sol) \\
\hline & Erkek & & 18,82 & 108,4 & 18,82 & 3,82 (sağ) & 6,32 (sağ) & 3,19 & 3,68 & 16,50 (sağ) \\
\hline & & & & & & 3,97 (sol) & 6.63 (sol) & 3,01 & 3,63 & 16,61 (sol) \\
\hline
\end{tabular}

Vücut kompozisyonları ile ilgili ölçümler deri altı yağ dokusunu belirlemede önemli ve değerli ölçümlerdir (18). Triceps ve subscapular yağ dokusu kalınlığı ile ilgili yapılan çalışmalar karşılaştırıldığında yağ dokusu ölçümlerinde popülasyonlar arası farkllıklar olduğu görülmektedir
$(16,18)$ Ayrıca, deri altı yağ dokusu kalınlığı ölçümü çocuklarda vücut yağ kompozisyonunun değerlendirilmesinde önemli bir parametredir. Deri altı yağ dokusu kalınlığı kardiyovasküler riskin belirleyicisi olmasına rağmen, BKi ile birlikte değerlendirildiğinde çocuklarda artmış vücut yağını 
daha doğru olarak gösterebilmektedir. Triceps deri altı yağ dokusu kalınlığı, çocukluk hipertansiyonunun bağımsız olarak göstergesi olduğu ve kan basıncı ile pozitif korelasyon gösterdiği belirtilmiştir (3). Ayrıca triceps deri altı yağ dokusu kalınlığının 5 yaş ve altında 5 mm'den az olmasının malnütrisyonun en önemli göstergesi olduğu vurgulanmıştır (17). Ayrıca, Yosmaoğlu ve ark.larının yaptıkları çalışmada erkeklerde triceps deri altı yağ dokusu kalınlığı BKI ile yüksek düzeyde pozitif korelasyon gösterdiği belirtilmiştir (Tablo 7). Literatürde çalışmamıza benzer şekilde triceps deri altı yağ dokusu kalınlığı ölçümlerinin kızlarda aynı yaş grubunda erkeklere göre daha fazla olduğu görülmüştür $(3,6,10,17,22-24)$. Biceps deri altı yağ dokusu kaIınlığı literatüre benzer şekilde aynı yaş grubunda kızlarda erkeklere göre daha fazla bulunmuştur $(6,23,24)$. Suprailiak yağ dokusu ölçümleri incelendiğinde, bazı kaynaklarda aynı yaş grubunda yer alan kızlarda erkeklerden daha kaIın olduğu belirtilmiştir (22-24). Subscapular deri altı yağ dokusu kalınlığı ölçümünde ise kızlarda erkeklerden daha fazla değer elde edilmiştir (6, 22 - 24). Ayrıca, subscapular deri altı yağ dokusu kalınlığı erkeklerde yaş ile birlikte artış gösterirken, triceps yağ dokusu kalınlığı ölçümü ise kızlarda 6 yaşından itibaren yaşla pozitif yönde artış göstermiştir ve kızlarda yağ dokusu kalınlığı erkeklerden anlamlı olarak fazla bulunmuştur $(16,20,21)$.

Sağlıklı 10-15 yaş arası çocuklarda deri altı dokusu yağ kalınlığını belirlemek için yapılan bir çalışmada 13 yaş sonrasında kızlarda aynı yaşta erkeklere göre vücut yağ artışının nedeni olarak kötü beslenme, düzenli egzersiz yapımaması ve düşük sosyoekonomik durum gösterilmiştir. Aynı çalışmada 10 yaş grubunda subscapular ve triceps deri altı yağ dokusu kalınlığı kızlarda erkeklerden daha fazla olduğu, 12 yaş grubunda ise biceps, triceps ve subscapular deri altı yağ dokusu kalınlığı erkeklerde daha az olduğu bulunmuştur. 13-15 yaş arasında deri altı yağ dokusu kalınlığı yaşla birlikte kızlarda erkeklere göre artış eğilimi gösterirken böyle bir artışa erkeklerde rastlanılmadığı bildirilmiştir (6). Çiçek ve ark.ları, çocuklarda vücut yağ oranının normalden düşük olmasının performans, sağlık ve büyüme yönünden olumsuz etkilere yol açabileceğini, fazla olan vücut yağının ise taşınması gereken fazla bir yük olduğunu, normal kardiyak ve pulmoner fonksiyona engel teşkil edebileceğini de bildirmişlerdir. Uluslararası sınıflandırmalara göre erkek çocuklar için 50 persentile denk gelen skinfold toplamının ise normal vücut yağ oranını gösterdiğini belirtilmiştir (24).

Neyzi ve ark.larının Türk çocuk populasyonunda yaptıkları çalışmada 50 persentil değerinde 3-6 yaş arası kızlarda vücut ağırlığı sırasıyla $14,18 \mathrm{~kg}, 16,1 \mathrm{~kg}, 18,4 \mathrm{~kg}$ ve $20,6 \mathrm{~kg}$ iken erkeklerde sırasıyla 14,83 kg, 16,8 kg, 18,6 kg ve 20,7 $\mathrm{kg}$ olarak ölçülmüştür. Boy uzunluğu 50 persentil değerinde 3-6 yaş arasında kızlarda sırasıyla 95,4 cm, 102,5 $\mathrm{cm}, 109,1 \mathrm{~cm}$ ve $115,1 \mathrm{~cm}$ iken aynı yaş grubunda ve aynı persentil değerinde erkeklerde $96,8 \mathrm{~cm}, 104,0 \mathrm{~cm}, 110,4$ $\mathrm{cm}$ ve $116,1 \mathrm{~cm}$ olarak bulunmuştur. BKI parametresi 3-6 yaş arasında 50 persentil değerinde kızlarda sırasıyla 15,5 $\mathrm{kg} / \mathrm{m}^{2}, 15,4 \mathrm{~kg} / \mathrm{m}^{2}, 15,4 \mathrm{~kg} / \mathrm{m}^{2}$ ve $15,5 \mathrm{~kg} / \mathrm{m}^{2}$ iken erkeklerde aynı ölçümler sırasıyla $15,9 \mathrm{~kg} / \mathrm{m}^{2}, 15,7 \mathrm{~kg} / \mathrm{m}^{2}, 15,5$ $\mathrm{kg} / \mathrm{m}^{2}$ ve $15,4 \mathrm{~kg} / \mathrm{m}^{2}$ olarak hesaplanmıştır. Baş çevresi 3.yaşta kızlarda ve erkeklerde 50 persentilde $48,7 \mathrm{~cm}$ ve $50,0 \mathrm{~cm}$ olarak ölçülmüştür $(25,26)$. Çalışmamızda kız ve erkek populasyonuna ait vücut ağırlığı ortalaması Neyzi ve ark.larının belirtmiş olduğu 50 persentil değerinin üzerinde olduğu görülmüştür. Boy uzunluğu parametresi erkeklerde Neyzi ve ark.larının yapmış olduğu 50 persentil değerinin üzerinde olduğu ancak kızlarda 3 yaş sonrasında 50 persentil değerinin altında olduğu görülmüştür. BKI ölçümü incelendiğinde ise kızların 50 persentil değerinin üzerinde seyrettiği ancak erkeklerde 3.yaş hariç 4-6 yaş arasında 50 persentil değerinin altında olduğu bulunmuştur. Literatürde de belirtildiği gibi görülen bu farklıklara genetik, beslenme durumu, sosyo ekonomik koşullar gibi faktörlerin neden olduğu söylenebilir.

Türkiye'de değişik bölgelerde yapılan çalışmalarda üst kol çevresi 3 yaş ile 5 yaş arasında kızlarda $15,4 \mathrm{~cm}$ ile 16,5 $\mathrm{cm}$, erkeklerde ise $15,5 \mathrm{~cm}$ ile $16 \mathrm{~cm}$ arasında olarak ölçülürken (11), Sarıtekin ve ark.ları aynı parametreyi 2-6 yaş arasında kizlarda $16,79 \mathrm{~cm}$, erkeklerde ise 16,92 cm (17), Özkoçak ve ark.ları yaşları ortalaması sırasıyla 8,85 yıl ve 8,30 yıl olan kız ve erkeklerde aynı ölçümü $21,95 \mathrm{~cm}$ ve $21,54 \mathrm{~cm}$ olarak bulmuşlardır (22). Bizim çalışmamız ile literatür karşılaştıııldığında Özkoçak ve ark.larının çalışmalarından daha düşük değer elde edilmiştir. Görülen farklıIıkların oluşmasında yaş, genetik özellikler, sosyoekonomik farklıklar, beslenme gibi etkenlerin rolü olduğu görülmektedir.

Literatüre bakıldığında 3-6 yaş arası çocuklarda somatotip analiz yapılan çalışmaya rastlanılmazken özellikle spor dallarında, dans ve jimnastik alanlarında somatotip incelemelerin olduğu çalışmalara oldukça sık rastlanmaktadır. Ingiltere'de Livv ve arkadaşlarının yaptığı çalışmada yaş ortalaması $21,07 \pm 4,48$ olan profesyonel balerinler, modern dansçılar ve eşli dans yapanların endomorf değerleri sırasıyla; $3,59 \pm 0,84,3,79 \pm 1,07$ ve $2,72 \pm 0,67$, mezomorf değerleri sırasıyla; $3,43 \pm 1,07,4,07 \pm 0,97$ ve $2,73 \pm$ 0,81 , ektomorf değerleri sırasıyla; $3,65 \pm 0,96,3,29 \pm 5,20$ ve $3,54 \pm 0,78$ olarak bulunmuş (27). Mersin Üniversitesi Devlet Konservatuvarı Bale Bölümü'nde yapılan $10-18$ yaş arası kız öğrencilerin endomorf değeri; $3,18 \pm 0,96$, mezomorf değeri; $3,53 \pm 0,92$ ve ektomorf değeri; 4,33 $\pm 0,94$ olarak bulunmuş (28). Çukurova Üniversitesi Devlet Konservatuvarı Bale Bölümü'nde yapılan 8-11 yaş arası kız öğrencilerin endomorf değeri; $2,63 \pm 0,55$, mezomorf değeri; $4,17 \pm 0,75$ ve ektomorf değeri; $4,03 \pm 0,95$ olarak bulunmuş (29). Özkoçak ve ark.' larının 7-10 yaş arası yüzme yapan öğrencilerde yaptığı çalışmada somatotip analiz değerleri kı öğrencilerde; 4.7-5.1-3.0 iken erkek öğrencilerde; 4.2-5.7-2.8 olarak bulunmuş (30). Ayan ve Kavi'nin 
yapmış olduğu 8-14 yaş arası yüzme yapan kız öğrencilerde yaptığı çalışmada ise somatotip analiz sonuçları 3,74,3-2,2 olarak bulunmuştur (31). Yine aynı çalışmada Küba'lı kız yüzme öğrencilerinde somatotip analiz sonuçlarının 2,8-3,3-2,6 olduğu, Belçika'lı kız yüzme öğrencilerinde ise 3,3-3,4-3,8 olarak bulunduğu belirtilmiştir (31). Gür ve ark.'larının yaş ortalaması $6,96 \pm 10,29$ olan kız futbol öğrencilerinde yaptığı bir çalışmada ektomorf $2,6 \pm, 1,1$; mezomorf $3,7 \pm 1,0$; ve endomorf $3,60 \pm 0,7$ değerleri bulunmuştur (32). Bizim çalışmamızda ise kız öğrencilerde ektomorf $1,41 \pm 1,11$; mezomorf $2,87 \pm 0,51$; ve endomorf $2,05 \pm 0,41$ iken erkek öğrencilerde ektomorf $2,03 \pm 1,21$; mezomorf 2,94 $\pm 1,02$; ve endomorf 2,63 $\pm 0,63$ olarak bulunmuştur. Literatür ile ölçümlerimiz arasındaki farklılıklar olduğu, bu farklııkların yaş ve cinsiyet gibi faktörlerden kaynaklanabileceği gibi genetik faktörlerin, ırkın, beslenme durumunun da, bu farklılıkların oluşmasında rol oynadığını söyleyebiliriz.

Büyüme ve gelişme, genetik, hormonal ve çevresel faktörlerin etkilisi ile antropometrik ölçümlerle izlenebilen bir süreçtir. Bu etkenler, coğrafik koşullar, sosyo-ekonomik farkIılıklar, toplumlar arasında ya da aynı toplumun bireyleri arasında farklılıklara yol açabilir. Erişkinlerde nispeten daha sabit değerler izlenebilmektedir. Çocuklarda intrauterin dönemden epifizlerin kapandığı 18 yaşa kadar süren ve değişen büyüme, gelişme sürecinin fiziksel ölçümlerle izlenmesinin önemli olduğu bildirilmektedir $(6,7)$. Çalışmamızda da 3-6 yaş arası çocukların fiziksel gelişimleri antropometrik ölçümlerle değerlendirilmiştir. Sonuç olarak her iki cinsiyette de gelişim benzerlik göstermektedir. Çalışmamı 3-6 yaş arasında somatotip analizin yapıldığı ilk çaış̧ma olmasından dolayı önem taşımaktadır. Bununla beraber, çocuklarda fiziksel gelişimin takip edildiği bu tür çaıışmaların daha fazla sayıda kişilerle yapılması ve devamIılığın sağlanması gerektiğini düşünmekteyiz.

\section{Kaynaklar}

1. Yılmaz T, Akın D, Aydın AD, Büyükmumcu M. Tıp fakültesi öğrencilerinin antropometrik olarak vücut ölçümlerinin değerlendirilmesi. Selçuk Tıp Dergisi 2013;29(1):1-4.

2. Otman AS, Köse N. Tedavi Hareketlerinde Temel Değerlendirme Prensipleri. Ankara: Pelikan Kitabevi, 2014; 50-120.

3. Khadilkar A, Mandlik R, Chiplonkar S, Khadilkar V, Ekbote V, Patwardhan V. Reference centile curves for triceps skinfold thickness for Indian children aged 5-17 years and cut-offs for predicting risk of childhood hypertension: a multi-centric study. Indian Pediatr 2015;52: 675-80.

4. Ferrari EP, Silva DAS, Martins CR, Fidelix YL. Morphological characteristics of professional ballet dancers of the bolshoi theater company. Coll Antropol 2013; 2: 37-43.

5. Ergun N, Baltacı G. Spor Yaralanmalarında Fizyoterapi ve Rehabilitasyon Prensipleri. Ankara: Hacettepe Üniversitesi Yayınevi, 1997.

6. Kavak $\mathrm{V}$. The determination of subcutaneous boy fat percentage by measuring skinfold thickness in teenagers in Turkey. International Journal of Sport Nutrition and Exercise Metabolism 2006;16:296304.

7. Zorba E, Ziyagil MA. Vücut kompozisyonu ve ölçüm metodları. Trabzon: Gen Matbaacllık Reklamcilık Ltd.Şti., 1995;144-5.
8. Mazıcıoğlu MM. Büyüme gelişme izleminde kullanılan antropometrik ölçüm yöntemleri: Büyüme takibinin metodolojisi. Türk Aile Hekimliği Dergisi 2011; 15(3): 101-8.

9. Çelik A, Günay E, Aksu F. 7-9 yaş grubu ilköğretim öğrencilerinin fiziksel ve motorik özelliklerinin değerlendirilmesi. DEÜ Tıp Fakültesi Dergisi 2013; 27 (1): 7-13.

10. Yosmaoğlu HB, Baltacı G, Derman O. Obez adolesanlarda vücut yağı ölçüm yöntemlerinin etkinliği. Fizyoterapi Rehabilitasyon 2010;21(3):125-31.

11. Özdemir MS. Üst orta kol çevresi ölçümünün 1-5 yaş arası Türk çocuklarda malnütrisyon tanısında kullanılan Gomez, Waterlow ve Dünya Sağlık Örgütü sınıflandırmaları ile bağlantısı. Tıpta Uzmanlık Tezi, Konya Selçuk Üniversitesi Tıp Fakültesi, Konya, 2014.

12. Hasan K. Edirne iline bağı ilkokullardaki (Şehit Asım Illköğretim Okulu ve Trakya Üniversitesi Devlet Konservatuvarı İlköğretim Okulu) 8-11 yaş arasındaki öğrencilerin eurofit testleri ile fiziksel kondisyonlarının değerlendirilmesi. Yüksek Lisans Tezi, Trakya Üniversitesi Sağlık Bilimleri Enstitüsü, Edirne, 2008.

13. Kızılakşam E. Edirne III merkezi ilköğretim okullarındaki 12-14 yaş grubu aktif olarak spor yapan ve yapmayan öğrencilerin eurofit test bataryaları uygulama sonuçlarının karşılaştıııması. Yüksek Lisans Tezi, Trakya Üniversitesi Sağlık Bilimleri Enstitüsü, Edirne, 2006.

14. Council of Europe (homepage on the internet). Sport Testing Physical Fitness Eurofit Experimental Battery Provisional Handbook. Strasburg, 1983.(Updated March 2011; Cited 24 January, 2019). Available from:www.bitworks-engineering.co.uk

15. Köklü Y, Özkan A, Utku Alemdaroğlu, Ersöz G. Genç futbolcuların bazı fiziksel uygunluk ve somatotip özelliklerinin oynadıkları mevkilere göre karşılaştırılması. Spormetre Beden Eğitimi ve Spor Bilimleri Dergisi 2009; 7(2): 61-8.

16. Ojo G, Adetola $O$. The relationship between skinfold thickness and body mass index in estimating body fat percentage on bowen university students. Int Biol Biomed J 2017;3(3):138-44.

17. Sarıtekin S, Dindar I. Edirne merkez kreş ve anaokullarına kayıttı 26 yaş grubu çocukların büyüme gelişme durumları ve etkileyen etmenler. Ankara Sağlık Hizmetleri Dergisi 2013;12(1):11-24.

18. Addo $\mathrm{Y}$, Himes JH. Reference curves for triceps and subscapular skinfold thicknesses in US children and adolescents. Am J Clin Nutr 2010;91:635-42.

19. Jenhek M, Demirciyan A. Triceps and subscapular skin-fold thickness in French-Canadian school-age children in Montreal. The American Journal of Clinical Nutrition 1972;25:576-81.

20. Marrodán MD, Montero de Espinosa MG, Herráez A, Alfaro EL, Bejarano IF, Carmenate MM. Subscapular and triceps skinfolds reference values of Hispanic American children and adolescents and their comparison with the reference of Centers for Disease Control and Prevention (CDC). Nutr Hosp 2015;32(6):2862-73.

21. Chumlea C, Knittle JL, Roche AF, Siervogel RM, Webb P.Size and number of adipocytes and measures of body fat in boys and girls 10 to 8 years of age. The American Journal of Clinical Nutrition. 1981; 34; 1791-7.

22. Özkoçak V. Hınçal SH. Gültekin T. Bektaş Y. 5-14 yaş grubu çocukların antropometrik değerleri ve somatotipik özellikleri. Akademik Sosyal Çalışmalar Dergisi 2018;6(67):53-61.

23. Deurenberg $P$, Pieters JJL, Hautvast JGAJ. The assessment of the body fat percentage by skinfold thickness measurements in childhood and young adolescence. British Journal of Nutrition 1990;63:293-303.

24. Cicek B, Ozturk A, Unalan D, Bayat M, Mazicioglu MM, Kurtoglu S. Four site skinfolds and body fat percentage references in 6-to 17 year old Turkish children and adolescents. J Pak Med Assoc 2014;64:1154-61.

25. Neyzi O, Günöz H, Furman A, Bundak R, Gökçay G, Darendeliler $F$, Baş $F$. Türk çocuklarında vücut ağırlığı, boy uzunluğu, baş çevresi ve vücut kitle indeksi referans değerleri. Çocuk Sağlığı ve Hastalıkları Dergisi 2008;51:1-14. 
26. Olcay Neyzi Persentil Değerleri. (homepage on the internet). Turkiye: Persentil Değerleri (cited: 21 January, 2019). Available from; https://olcay neyzi persentil değerleri.

27. Livv H, Wyon MA, Jürimae T, Saar M, Maestu J, Jürimae J. Anthropometry somatotypes and aerobic power in ballet contemporary dance and dancesport. Medical Problems of Performing Artists 2013; 207-11.

28. Arınlı Y. Adölesan dönemdeki bale öğrencilerinde beslenme alışkanlıklarının büyüme hormonu üzerine etkisi. Yüksek Lisans Tezi, Mersin Üniversitesi Sosyal Bilimleri Enstitüsü, Mersin, 2013.

29. Kabakcı AG, Yücel AH. Klasik bale eğitimi alacak öğrencilerin somatotip analizi. Cukurova Medical Journal 2016; 41: 744-50.

30. Özkoçak V. Hınçal SH. Gültekin T. Bektaş Y. 7-10 yaş arası yüzme yapan çocuklarda antropometrik ve somatotip değişkenler. Hitit Üniversitesi Sosyal Bilimler Enstitüsü Dergisi 2018; 11(2): 1338-46.

31. Ayan V, Kavi N. 8-14 yaş arası kız yüzücülerin somatotip yapılarının ve yatay sıçrama özelliğinin incelenmesi. International Journal of Science Culture and Sport 2016; 4(1): 23-30.

32. Gür $F$, Ayan V, Yüksek $S$. Kız çocuklarının futbol branşı için somatotip ve performans özelliklerinin incelenmesi. International Journal of Science Culture and Sport 2016; 4(1): 358-67. 